\title{
EL FEDERALISMO ARGENTINO A DEBATE: ARGUMENTOS EN DEFENSA DE UN MODELO DEMOCRÁTICO DELIBERATIVO DE GOBIERNO FEDERAL. ${ }^{\prime}$
}

\author{
NICOLÁS EMANUEL OLIVARES²
}

\section{Resumen.}

Este trabajo de investigación tiene por objetivo general reconstruir y evaluar dos modelos democráticos contemporáneos pero disímiles que tienen por epicentro el concepto de federalismo. Un primer modelo de tipo federal pluralista impropio surgió en 1994, año en el cual se sancionó la última reforma constitucional argentina. Un segundo modelo de tipo federal deliberativo se propone aquí como salida adecuada a las objeciones normativas del primer modelo. El primer enfoque federal promueve un poder ejecutivo nacional fuerte, en tanto árbitro y/o mediador en los procesos de concertación habidos entre las provincias argentinas. En este primer modelo, el principio de resolución de conflictos es el de negociación y promueve un sistema hiperpresidencial capaz de someter a las provincias a criterios evaluativos los cuales están prefijados en la constitución nacional de 1994. El segundo enfoque de tipo deliberativo promueve un gobierno político más descentralizado, con una dinámica cooperativa entre poderes constituidos nacionales y subnacionales. En este segundo modelo el principio de resolución de conflictos propuesto es el argumentativo y el gobierno nacional adoptaría un sistema semipresidencial en el cual se evaluaría el proceder de cada entidad subnacional en función de criterios

$1 \quad$ El presente trabajo fue desarrollado en el marco de una Beca de investigación Posdoctoral Interna del CONICET (2017-2019), siendo el título del proyecto: "Federalismo, Teoría no ideal y Republicanismo". Agradezco a R. Gargarella, S. Linares, M. Alegre, L. Villavicencio Miranda, E. Llamosas y M. Moroni y E. Zimmermann, por sus generosos comentarios efectuados a una versión preliminar de este trabajo.

2 Profesor en Derecho Constitucional (UNLPam). IEHSOLP-UNLPam, Santa Rosa, La Pampa (Argentina). olivares.nicolasemanuel@gmail.com 
establecidos durante un debate político previo entre los organismos afectados.

\title{
Palabras clave:
}

Constitucionalismo argentino; democracia contemporánea; federalismo pluralista impropio; federalismo deliberativo.

\begin{abstract}
.
This research work has the general objective of reconstructing and evaluating two contemporary but dissimilar democratic models that have as their epicenter the concept of federalism. A first improvised pluralistic federal model emerged in 1994, the year in which the last Argentine constitutional reform was sanctioned. A second model of a deliberative federal type is proposed here as an adequate outlet for the normative objections of the first model. The first federal approach promotes a strong national executive power, as arbitrator and/or mediator in the concertation processes between the Argentine provinces. In this first model, the principle of conflict resolution is that of negotiation and promotes a hyperpresidential system capable of subjecting the provinces to evaluative criteria which are prefixed in the national constitution of 1994. The second approach of deliberative type promotes a political government more decentralized, with a cooperative dynamic between constituted national and subnational powers. In this second model, the principle of conflict resolution proposed is argumentative and the national government would adopt a semi-presidential system in which the procedure of each subnational entity would be evaluated according to criteria established during a previous political debate between the affected organizations.
\end{abstract}

\section{Keywords:}

Argentine constitutionalism; contemporary democracy; improper pluralistic federalism; deliberative federalism.

\section{Introducción.}

Habitualmente el federalismo ha sido definido por los constitucionalistas contemporáneos como una forma de estado (Hernández, 1997; Sabsay, 1998; Bazán, 2013). En este entendimiento el federalismo tendría 
implicancias en las consabidas cuatro dimensiones del concepto moderno de Estado, a saber: territorio, población, poder y gobierno. Desde esta perspectiva estatista, el federalismo, suele ser conceptualizado como aquella teoría constitucional que promueve la defensa de principios federales a los fines de señalar cuáles son las facultades concurrentes y exclusivas de las unidades políticas que conforman un estado nacional federal general. A diferencia de un estado nacional unitario, la soberanía y/o autonomía en los órdenes políticos federales suele estar diferenciada, a menudo de manera constitucional, entre al menos dos niveles de gobierno, de modo que las unidades en cada nivel tienen cierta autoridad final y pueden autogobernarse en alguna área temática. Por lo tanto, los ciudadanos en un estado nacional federal poseen obligaciones políticas y derechos garantizados por, al menos, dos autoridades, una nacional o federal general y otra local o federal particular, lo cual no excluye una tercera autoridad de tipo municipal o comunal (Follesdal, 2018: § 1). ${ }^{3}$

Sin embargo, recientemente la teoría política ha analizado la cuestión federal desde una perspectiva más amplia a la vez que compleja, ya que piensa al federalismo como una forma de gobierno democrático. En este sentido, cabe advertir que el federalismo, en tanto teoría sobre las formas de gobierno democráticas, ha recibido recientemente una gran atención filosófica, por dos motivos. Por un lado, se han abordado los dilemas y oportunidades que enfrentan diversas naciones, tales como Canadá, Barcelona, El País Vasco, Escocia, Crimea, por mencionar solo algunas áreas donde los acuerdos federales se consideran soluciones interesantes para acomodar las diferencias entre poblaciones afligidas por divisiones étnicas, culturales, religiosas, y/o lingüísticas, que aún buscan un orden político común democrático (Follesdal, 2018: §1). Por otro lado, se ha comenzado a hacer extensivas al estudio del federalismo las categorías de análisis empleadas por la teoría democrática contemporánea, habitualmente empleadas para estudiar las formas de gobierno presidenciales $y$

3 En contraste, el término confederación ha llegado a significar un orden político con un gobierno central más débil que el de una federación. Por lo general, en una confederación a) las unidades miembros pueden secesionar; b) el gobierno central solo ejerce la autoridad delegada por las unidades subnacionales; c) el gobierno central está sujeto al veto de las unidades miembros en diversos tópicos; d) las decisiones del gobierno central obligan a las unidades subnacionales pero no a los ciudadanos directamente; e) el gobierno central carece de una base fiscal o electoral independiente; y/o f) las unidades subnacionales no ceden la autoridad permanentemente al gobierno central; y f) las confederaciones a menudo emergen de pactos destinados a que un gobierno común cumplimente ciertas tareas específicas (Follesdal, 2018: § 1). 
parlamentarias, analizando no solo la estabilidad y legitimación de la forma de gobierno federal, sino también la aceptabilidad y sustentabilidad normativa del ideal regulativo federal (Nino, 1997; González Bertomeu, 2008).

En el marco de esta novel línea de investigación en filosofía política, consideramos que el federalismo no puede ni debe ser reducido a una forma de estado, sino que debe ser entendido y analizado en sus condiciones normativas no ideales contemporáneas como una forma de gobierno. A mayores precisiones, en este trabajo emplearemos el concepto de federalismo en tanto forma democrática de gobierno, no solo en un sentido descriptivo, sino también normativo, El sentido descriptivo refiere a los sistemas federales reales, es decir a tal como son en el mundo político real dichos sistemas de gobierno. El sentido normativo, hace alusión a un determinado ideal regulativo democrático federal, el cual fija los criterios normativos de corrección y evaluación de las instituciones, normas y medidas políticas federales realmente existentes (González Bertomeu, 2008).

Partiendo de dicha estructura de análisis es que nos avocaremos a estudiar y evaluar el federalismo argentino contemporáneo, emergente de la última reforma constitucional de 1994. Los especialistas coinciden en que dicho proceso reformista, se propuso discutir dos temas centrales para la vida política de nuestro país: el presidencialismo y el federalismo. Los objetivos explícitos, aunque retóricos, eran moderar el primero, así como ampliar el segundo. A más de veinticinco años de aquel proceso constituyente numerosos y destacados especialistas en historia y teoría constitucional parecen coincidir en que el diagnóstico es el de un doble fracaso. Por un lado, el presidencialismo argentino ha reforzado su cariz decisionista, cesarista y antirrepublicano. Por otro lado, el federalismo argentino ha permanecido acotado, limitado y no ha crecido en sus aspectos formal institucional ni cívico ciudadano (Gargarella, 2014).

Atendiendo a dicho marco teórico, es que el presente trabajo de investigación se propone efectuar los siguientes pasos argumentativos: 1) Explicitar argumentos en defensa de que el federalismo no puede ni debe ser reducido a una forma de estado, sino que constituye una particular forma de gobierno democrático; 2) Reconstruir las particularidades normativas y objeciones de las que es pasible el sistema federal argentino desde la última reforma constitucional nacional acaecida en 1994; 3) Identificar aquellos elementos normativos que vuelven al federalismo argentino un modelo 
democrático pluralista impropio, esbozando las desventajas normativas que dicho enfoque posee; 4) Proponer un modelo federal deliberativo en tanto ideal regulativo superador, señalando las ventajas que ostenta en relación al modelo federal pluralista impropio vigente

\section{EI federalismo como forma de gobierno democrática contemporánea.}

Por un lado, el federalismo constituye una forma de gobierno dado que implica una particular concepción acerca de la legitimidad política. La perspectiva democrática federal considera legítimas aquellas instituciones, normas y medidas políticas, si y solo si, respetan cierta autonomía y autogobierno de cada unidad estatal formal, sea nacional, regional, provincial, comunal, o municipal. El federalismo en tanto forma de gobierno varía según la concepción de democracia desde la cual parte, pudiendo identificarse actualmente un federalismo pluralista, un federalismo populista y un federalismo deliberativo, entre otros. Por otro lado, el federalismo promueve una determinada forma de estado, dado que implica una estructura política general que determina un funcionamiento específico de los elementos de un estado nacional, a saber: territorio, población, gobierno, legislación. En este sentido, como hemos señalado, el federalismo en tanto forma de estado puede variar de una confederación, con soberanía múltiple, a una federación nacional, con autonomía restringida de sus unidades subnacionales.

De este modo, si nos detenemos en un concepto normativo de federalismo estamos indicando que estudiaremos las distintas maneras en que puede ser concebido el ideal regulativo federal, el cual admitiría un cumplimiento gradual y parcial en el marco de un horizonte democrático. Más allá de este carácter normativo que atribuimos al concepto de federalismo, consideramos insoslayable pensarlo desde una perspectiva contextualizada, situada, es decir histórica, dado que dicha forma de gobierno y estado constituye “...el producto de dinámicas e inercias históricas, políticas y culturales en la vida de un país..." (González Bertomeu, 2008: 442). ${ }^{4}$ Ello implica asumir una

$4 \quad$ Por su parte J. F. González Bertomeu señala que el análisis normativo y el análisis histórico político marchan por carriles separados, asumiendo con ello una perspectiva clásica historiográfica cercana a la historia de las ideas y sus sabidas distancias con una filosofía política normativa. La historia desde esta perspectiva tradicional e entendida como un ámbito plenamente empírico y causal desde el cual se pretende explicar, justificar y reconstruir intelectualmente los hechos ocurridos en la realidad (González Bertomeu: 2008: 443). Por el contrario, la historia conceptual de lo político considera que lo normativo es inherente al mismísimo proceso histórico político, es decir, afirma que los ideales regulativos se 
perspectiva normativa no ideal sobre el concepto normativo-descriptivo de federalismo.

En cuanto a una brevísima historia latinoamericana conceptual de lo político del término federalismo, cabe afirmar que el ideario federal, federalismo, o perspectiva federalista, puede y debe ser pensada como una concepción política compleja, en tanto no solo incluye una forma de estado sino también una forma de gobierno. Los federalistas de la segunda mitad del siglo XVIII y primera mitad del siglo XIX así lo entendían. El federalismo no solo era a su entender una forma de organizar el poder estatal sino una modalidad especifica mediante la cual gobernar. El federalismo era en aquel entonces mucho más que una forma de estado era una ideología o tradición política, así como daría nombre entre 1820 y 1852 a un partido político. En particular, cabe destacar que tras las revoluciones norteamericana e hispanoamericanas la idea de soberanía se plegó sobre si misma dando origen a una escisión fundamental entre soberanía y gobierno, entre principios de estado y técnicas de gobierno (Palti, 2018: 66-68). Este clivaje se evidenció con mayor claridad en la segunda mitad del siglo XIX, cuando la idea de federalismo se vio resignificada en el marco de una nueva constelación semántica, conforme la cual la nación era la única soberana, mientras que las provincias y ciudades serian ahora meras unidades subnacionales autónomas. En particular cabe señalar que en la constitución argentina de 1853, reformada en 1860 y 1866 , el federalismo aparece ya como una forma de estado, dejando de lado otros usos semánticos propios de la primera mitad del siglo XIX, en un claro proceso de liberalización del lenguaje político argentino (Agüero, 2014; Olivares, 2018).

La discusión política entre federales y unitarios, habida en el espacio político rioplatense del siglo XIX puede traducirse en el debate entre quienes deseaban "juntarse" y aquellos que sostenían que "debían mantenernos juntos" (González Bertomeu, 2008: 458). Por un lado, los partidarios de la primera perspectiva, es decir de "juntarse", presuponen la soberanía de las provincias, desde la cual podría y debía protegerse un destino político común. Por otro lado, quienes eran defensores de la segunda alternativa, relativa a "mantenerse juntos", buscaban imponer un sentido de nacionalidad preexistente a la constitución nacional de 1853 . La primera perspectiva fue la asumida por federales partidarios de una

construyen, enuncian, justifican y critican en un determinado contexto discursivo donde existe cierta constelación semántica y una gramática política predominante (Rosanvallon, 2016: 1-10; Palti, 2009: 1-9). 
confederación plena, tales como J. G. Artigas y M. Dorrego, mientras que la segunda fue defendida con argucia tanto por J. B. Alberdi como B. Mitre, liberales partidarios de una federación acotada, aunque existían notorias diferencias entre ellos en sus argumentos (González Bertomeu, 2008: 460).

Luego durante el siglo XX, especialmente durante la segunda mitad de este, se produjo un complejo encubrimiento de las formas y doctrinas constitucionales, quedando en el olvido aquella perspectiva democrática republicana conforme la cual el federalismo debía ser entendido como una concepción política descentralizadora, sustentada en una definición no liberal de las nociones de libertad, soberanía, igualdad y democracia. El denominado fin de las ideologías, relatos nacionales e historia, implico entonces una despolitización notoria de la discusión sobre el termino federalismo, reduciéndose los estudios a comparaciones de los diseños institucionales realmente existentes de federaciones en el marco del denominado proceso de globalización (Palti, 2018: 265-273).

A finales del siglo XX y principios del XXI surgieron cada vez mayores reclamos de comunidades políticas que manifestaron sus deseos de obtener un mayor grado de autogobierno. Por un lado, los más radicales expresaron sus deseos de emanciparse políticamente, de secesionar. Los argumentos esgrimidos por dichas comunidades son variados y es creciente el número de casos, siendo paradigmáticos los de Cataluña, País Vasco y Escocia. Por otro lado, los más moderados se manifestaron en dirección a un mayor respeto por la pluralidad cultural, étnica, religiosa, y mayor grado de autonomía. Atento la relevancia, complejidad y actualidad de este proceso federalista glocal, es que consideramos relevante su investigación y estudio.

En respuesta a esta necesidad teórica es que en el presente trabajo nos avocaremos a reconstruir y evaluar dos modelos democráticos contemporáneos pero disímiles que tienen por epicentro el concepto de federalismo en el espacio político argentino. Un primer enfoque de tipo federal pluralista impropio surgió en 1994, año en el cual se sancionó la última reforma constitucional argentina. Un segundo enfoque de tipo federal deliberativo actualmente no vigente, ha sido tímidamente proyectado por reconocidos constitucionalistas contemporáneos (Nino, 1992, 1997; Gargarella, 2014; González Bertomeu, 2008).

El primer modelo federal, actualmente vigente, al cual denominaremos pluralista impropio, promueve un poder ejecutivo nacional fuerte, en tanto árbitro y/o mediador en los procesos de negociación habidos entre 
las unidades políticas subnacionales autónomas, es decir las provincias argentinas. En este segundo enfoque, el principio de resolución de conflictos es el de negociación y promueve un sistema hiperpresidencial capaz de someter a las provincias a sus criterios evaluativos los cuales están prefijados en la constitución nacional de 1994.

El segundo modelo de tipo deliberativo republicano, no actualmente vigente, promueve un gobierno político suficientemente descentralizado, con una dinámica cooperativa entre poderes constituidos nacionales y entre unidades políticas subnacionales. En este primer discurso el principio de resolución de conflictos es el argumentativo y el gobierno nacional adopta un sistema semipresidencial en el cual se evalúa el proceder de cada provincia en función de criterios preestablecidos durante un debate interprovincial fundacional previo (Nino, 1992, 1997; Gargarella, 2014; González Bertomeu, 2008).

\section{La reforma constitucional argentina de 1994 y la emergencia de un modelo federal pluralista impropio.}

Tras numerosas reuniones partidarias efectuadas desde fines de 1980 a principios de 1990, entre los miembros del radicalismo por un lado, así como del justicialismo por el otro, las cuales no produjeron reforma alguna, finalmente en 1993, los principales representantes de ambas fuerzas políticas, Raúl R. Alfonsín y Carlos S. Menem, firmaron dos pactos políticos complementarios, buscando el apoyo del resto de los partidos políticos democráticos (López Rosas, 1996: 666).

Por un lado, el 14 de Noviembre de 1993, firmaron el denominado "Pacto de Olivos" donde los signatarios proclamaron y coincidieron en presentar al pueblo de la República un proyecto de reforma constitucional, señalando que permanecería sin cambio alguno la parte dogmática de la Constitución de 1853 (López Rosas, 1996: 666-667).

Por otro lado, el 13 de diciembre de 1993 fue firmado el llamado "Pacto de la Rosada", suscripto por los jefes de ambos partidos políticos complementando así al Pacto de Olivos. El texto de este documento habría de servir de base para el proyecto de ley que declara la necesidad de la reforma ( $\left.\mathrm{N}^{\circ} 24.309\right)$ y estaba dividido en tres partes: a) núcleo de coincidencias básicas; b) temas habilitados para el debate constitucional; y c) mecanismos jurídicos y políticos para garantizar la concreción de los acuerdos (López Rosas, 1996: 667). 
Dichos pactos políticos encaminaron la reforma constitucional nacional de 1994, la cual tendría entre sus principales metas fortalecer el sistema federal de gobierno, lo que quedaría retóricamente plasmado en cinco objetivos específicos explícitamente asumidos en el seno de las deliberaciones, a saber; a) vigorización del senado nacional; b) constitucionalización del sistema de coparticipación federal; c) crecimiento armónico de la nación, sin distinción de provincias o regiones; d) autonomía municipal obligatoria en todas provincias; y e) creación de regiones interprovinciales y celebración de convenios internacionales entre una o más provincias y una o más naciones extranjeras (Bazán, 2013: 49-56).

En este nuevo contexto normativo el federalismo argentino era definido como una particular combinación de dos fuerzas: una centrípeta y la otra centrífuga. La primera, va de la periferia hacia el centro y supone la existencia de una unidad soberana denominada Estado Nacional Argentino. La segunda, va del centro hacia la periferia e implica cierta descentralización política lo cual permite la existencia de una pluralidad de provincias autónomas (Bazán, 2013: 42).

En el Estado federal argentino coexisten diversas entidades politicas: la nación, las provincias, los municipios, las regiones interprovinciales y la Ciudad Autónoma de Buenos Aires (CABA). En el marco de su autonomía, las provincias pueden sancionar sus propias constituciones, teniendo por límites el sistema representativo y republicano como forma de gobierno y conservando para sí todo el poder no delegado por la constitución nacional al gobierno federal, así como aquel que expresamente se hayan reservado mediante pactos políticos interprovinciales preexistentes a la nación argentina (Bazán, 2013: 42-43).

En este particular esquema de poderes políticos constituidos, existen tres tipos de relaciones en la estructura federal, a saber: i) de subordinación, cuando las entidades subnacionales se deben ajustan al ordenamiento normativo nacional; ii) de participación, en aquellas ocasiones en las cuales Nación y provincias participan de forma conjunta de ciertas decisiones del gobierno federal; y iii) de coordinación, referidas a ciertas circunstancias en las cuales se delimitan las competencias exclusivamente federales y aquellas provinciales, sin por ello negar su complementariedad (Bazán, 2013: 43-44).

El cariz centralista del sistema federal argentino se evidencia en todo su esplendor cuando en el Art. 128 de la Constitución Nacional, donde se afirma que los gobernadores de provincia constituyen invariablemente 
agentes naturales del gobierno federal, teniendo por principales objetivos políticos normativos: a) hacer cumplir la Constitución y las leyes de la nación, de conformidad con el principio de lealtad federal que los entes subnacionales deben prodigar al Estado Nacional; y b) contribuir, en la medida establecida por la norma fundamental nacional, al sostenimiento, desarrollo y progreso del federalismo de concertación (Bazán, 2013: 46).

En relación con la concepción y diseño federal adoptado tras la reforma de 1994, numerosos especialistas han señalado que el mismo podría ser cualificado como un federalismo de concertación (Hernández, 1997; Sabsay, 1998; Bidart Campos, 2016; Gelli, 2006; Quiroga Lavie, 2012; Sagües, 2012; Bazán, 2013; ). La característica que permitiría adjetivar de tal forma a nuestro sistema federal estaría dada por la sanción constitucional del principio de concertación entre nación, provincias y Ciudad Autónoma de Buenos Aires en el Art 75 inc. 2, cláusulas segunda y tercera, las cuales trascribimos a continuación:

Art 75 inc. 2. - Segunda Cláusula: "Una ley convenio, sobre la base de acuerdos entre la Nación y las provincias, instituirá regímenes de coparticipación de estas contribuciones, garantizando la automaticidad en la remisión de los fondos"

- Tercera Cláusula: "La distribución entre la Nación, las provincias y la Ciudad de Buenos Aires y entre estas, se efectuará en relación directa a las competencias, servicios y funciones de cada una de ellas contemplando criterios objetivos de reparto; será equitativa, solidaria y dará prioridad al logro de un grado equivalente de desarrollo, calidad de vida e igualdad de oportunidades en todo el territorio nacional."

En ambas cláusulas se refleja el principio de negociación, convenio o concertación, en materia de redistribución de ingresos fiscales, estableciendo ciertos criterios objetivos de reparto orientados a la obtención de la equidad de trato y de oportunidades en dicho proceso negocial. En dicho esquema, la Corte Suprema de Justicia de la Nación (CSJN) oficiaría como un árbitro supuestamente imparcial, neutral, equidistante que garantiza la equidad de trato y oportunidades de los afectados en el aspecto financiero (Sabsay, 1998; Gelli, 2006; Bidart Campos, 2016).

El procedimiento constitucional establecido para sancionar efectivamente con fuerza de ley nacional aquella ley-convenio de coparticipación federal, esta delineado por el Art 75 inc. 2 en su Cuarta cláusula y es el siguiente: 1) negociación entre nación, provincias y Ciudad Autónoma de Buenos Aires; 2) se ratifican ciertos acuerdos fiscales entre 
dichos sujetos políticos; 3) se inicia el proceso ordinario de sanción de una ley en el Congreso de la Nación, siendo la Cámara de Senadores el recinto de origen de dicho proyecto legislativo; 4) la mayoría absoluta de la totalidad de los miembros de cada Cámara debe de aprobar el proyecto legislativo; y 5) los sujetos políticos mencionados deben de ratificar, aprobar, sancionar con fuerza de ley local, aquella ley nacional general, siguiendo el trámite constitucional y legal prescripto para sus respectivos recintos legislativos (Gelli, 2006: 651).

Este modelo negocial en el aspecto financiero ha merecido numerosas y profundas críticas, entre las cuales, caben destacar las siguientes: a) ".. la ley vigente ha determinado un retroceso en relación con los criterios de distribución, porque no establece bases o pautas para ello, sino índices fijos para cada provincia, lo cual ha convertido al sistema en una negociación traumática para muchas provincias, que se han sentido relegadas en relación con otras por simples circunstancias políticas..."(Quiroga Lavié, 2012:377); b) “...necesariamente, para lograr la sanción de la ley de coparticipación de tan complejo trámite, se requieren trabajosas negociaciones y consensos, aunque todo parece indicar que se persistirá en la práctica por la cual el Estado Federal proyecta los acuerdos y arrastra en pos de sí a las provincias..." (Gelli, 2006: 649); c) la ambigüedad, amplitud, complejidad del proceso mediante el cual debiera de sancionarse aquella ley convenio permite que las prácticas políticas partidarias sesgadas por ciertos intereses locales impongan un esquema negocial en absoluto solidario y equitativo, lo cual ratifica la vigencia política y social de una práctica negocial por sobre una norma constitucional negocial (Gelli, 2006: 651); d) la dinámica constitucional sociológica del federalismo argentino actual deja lugar para una mutación constitucional gravísima de la constitución normativa o formal, conforme la cual el Estado Nacional saca ostensibles ventajas en la imposición de sus intereses por sobre el de las provincias y municipios, lo cual lleva a afirmar que existen normas constitucionales impuestas tras la reforma de 1994 que permiten la desfederalización, en tanto modificación de la forma democrática de gobierno federal (Bidart Campos, 2016: 60); e) el federalismo de concertación implementado constitucionalmente en 1994 debe ser analizado bajo la particular perspectiva federal asumida, la cual es de tipo mixta, híbrida, intermedia, lo cual conlleva adoptar una forma de gobierno que sin ser unitaria tampoco es propiamente federal, peor aún, cabe señalar que tras la última reforma constitucional argentina, el sistema federal originalmente planteado en la Constitución de 1853-1860 ha sufrido notorios desequilibrios, en favor del gobierno nacional y en desmedro de 
las unidades políticas subnacionales (Sagüés, 2007: 189-190); f) en la práctica política, la constitucionalización del sistema de coparticipación, produce un gran debilitamiento del sistema federal argentino, siendo que se erigió uno de los mecanismos que más han contribuido a acentuar la dependencia de las provincias al poder central (Bazán, 2013: 51; Dalla Vía, 2002: 68-69); y g) finalmente, más allá de la aspiración de la mayoría de los convencionales constituyentes de robustecer, profundizar y ampliar el sistema federal argentino, empíricamente ello no ha acaecido, sino que ha aumentado el centralismo, habiéndose en particular incrementado la subordinación financiera y económica de la mayoría de las provincias a la nación (Bazán, 2013: 58).

En este trabajo refrendamos dichas objeciones, así como postulamos que si se desea comprender acabadamente el modelo federal argentino establecido en 1994, entonces el principio de negociación no debe ser tomado de forma restringida como un principio propio del federalismo fiscal o si se prefiere económico, sino como un principio democrático más amplio, a saber cómo un criterio normativo de resolución de conflictos inserto en el núcleo duro de una concepción democrática pluralista impropia. Desde esta perspectiva ampliada y más compleja, la Corte Suprema de Justicia de la Nación oficia como un árbitro presuntamente imparcial, neutral, equidistante que garantiza la equidad de trato y oportunidades de los afectados, no solo en el aspecto financiero en particular, sino en todo otro conflicto político que se dé entre las unidades que componen la federación argentina. Esto último se ve reafirmado por lo normado en el actual Art 127 de la Constitución argentina, el cual señala que ante conflictos entre provincias, se prohíbe echar mano de violencia o coerción armada, es decir niega la posibilidad de dirimir el asunto mediante una guerra, correspondiendo a la Corte Suprema de Justicia de la Nación argentina dirimir las quejas entre provincias (Bidart Campos, 2016: 53).

Ahora bien, ¿qué consecuencias conceptuales posee superar una definición restringida de tipo financiera de la negociación?, o mejor dicho ¿qué implicancias normativas posee elevar el principio de negociación al rango de principio político fundamental?

$\mathrm{Al}$ respecto, J. L. Martí señala que existen al menos tres principios políticos de toma de decisiones los cuales se corresponden con tres modelos normativos diversos de democracia, a saber: negociación, voto y argumentación (Martí, 2006: 40-41). En primer lugar, el principio del voto establece que las decisiones colectivas deben basarse en las preferencias 
individuales de cada uno de los ciudadanos, considerados como agentes racionales, siendo que tales preferencias se consideran preconstituidas al proceso de votación, en tanto elemento externo. El modelo democrático contemporáneo que se condice con dicho principio es el que concibe a la democracia como un mercado, a veces denominado modelo libertario (Martí, 2006: 47-48). En segundo lugar, el principio de negociación, sostiene que la decisión y/o acuerdo político resulta de un proceso agregativo de acomodación de preferencias, concertación, concesión, en el que cada una de las partes defiende abiertamente sus preferencias individuales autointeresadas, siendo entonces el resultado del acuerdo determinable por la capacidad de negociación de las partes. El modelo democrático que se condice con este principio es el pluralista o poliárquico (Martí, 2006: 4849). En tercer lugar, el principio de argumentación promueve el diálogo o intercambio intersubjetivo en defensa de una propuesta o contra otra, dado en ciertas condiciones normativas de igualdad entre los participantes, siendo el criterio definitorio el del mejor argumento. El modelo democrático que resulta coherente con este principio es el deliberativo (Martí, 2006:49-50).

Tras analizar pormenorizadamente a dichos modelos normativos de democracia, J. L. Martí señala atractivos y objeciones de los que serían pasibles, siendo particularmente relevantes para nuestros propósitos las objeciones o problemas genéticos que ostenta el modelo democrático pluralista centrado en el principio de negociación. En este sentido, caben identificar tres objeciones fundamentales: 1) un marcado escepticismo frente a la idea de bien común el cual denota una notoria falta de confianza en la capacidad de actuación colectiva de la ciudadanía; 2) la negociación no aspira como tal a satisfacer criterios de justicia, legitimidad y/o verdad política, sino meramente pretende alcanzar cierto acomodamiento de pretensiones en función de la contingente y desigual capacidad de negociación de las partes; y 3) como consecuencia de lo anterior, este modelo y su principio permiten y/o promueven que ciertos sujetos individuales y/o colectivos con mayor poder de negociación prevalezcan incluso a expensas de satisfacer pobremente o incumplir por completo dichos criterios normativos de justicia, legitimidad y/o verdad (Martí, 2006: 68-70).

Atendiendo a este esquema intelectual de pensamiento es que en el subsiguiente apartado analizaremos nuestro sistema federal argentino, el cual, por los argumentos señalados y a señalar, cualifica como pluralista impropio. 


\section{Un modelo federal pluralista impropio.}

Desde una perspectiva filosófica política normativa, algunos autores consideran que pueden identificarse en la reforma constitucional de 1994 ciertos presupuestos propios de un modelo pluralista (Nino, 1992, 1997).

El concepto de pluralismo político refiere a dos enfoques conceptuales diferentes. El primer enfoque, llamado pluralismo social, afirma que en las sociedades democráticas occidentales contemporáneas conviven diversas concepciones de los social, las cuales pretenden ostentar cierto predominio sin ser hegemónicas. Sus principales exponentes son J. Rawls y W. Connolly y tiene por meta principal identificar el mejor método para equilibrar la diversidad de pretensiones sociales de aquellos grupos que conviven en una sociedad política contemporánea. El segundo enfoque, denominado pluralismo estructural, ha sido definido como una particular interpretación de la vida social que incluye tantas fuentes de autoridad como dimensiones de lo social existan, siendo indebido y/o imposible que una de aquellas domine a todas las restantes. Sus principales exponentes son R. Dahl y C. Lindblom y tiene por objeto principal la descentralización de la toma de decisiones dentro de una sociedad. (Pérez, 2017: 1-2).

En el primer enfoque corresponde citar las teorizaciones de W. Connolly, quien trabaja en la búsqueda de un concepto y una práctica de pluralismo que se diferencie, por un lado, de ciertos modelos "superficiales" y "seculares" que se han propuesto en el pasado, y, por el otro, de la idea de una nación fuertemente centralizada y unificada. En referencia a los primeros, cuyo caso paradigmático sería el de las teorías pluralistas liberales, W. Connolly sostiene ante todo que no son útiles para un mundo como el actual: vertiginoso, en permanente cambio y con una infinita multiplicidad de cosmovisiones. En cuanto a los segundos, constituirían una restricción a la libertad individual y al desarrollo de las diferencias dentro de la sociedad, por considerar que una nación solo puede desarrollarse si cuenta con una idiosincrasia unificada y un propósito en común (Pérez, 2017: 12).

W. Connolly denuncia dos errores en estas posturas: por un lado, sobreestiman la autonomía de la razón pública, mientras que, por el otro, subestiman la influencia de ciertos hábitos sociales y creencias morales comprehensivas en instituciones y prácticas políticas. El problema de esta perspectiva, según el autor, sería no percibir que los rituales y hábitos que acompañan una creencia moral comprehensiva forman parte integral de ella, y contribuyen a constituirla y asentarla tanto como su doctrina y su jerarquía de valores (Connolly, 2005: 57-58). En la práctica, estas posturas 
derivan en lo que Connolly llama tolerancia liberal, entendida como la aceptación pública de diferencias públicas, lo cual no solo mantiene a las minorías en un lugar de sujeción política, sino que también es inútil ante una política vertiginosa (Connolly, 2005: 123).

Por su parte, W. Connolly contrapone al modelo pluralista liberal un modelo pluralista dinámico, profundo, activo e integral. El modelo social propuesto consistiría en una amplia red de un denso pluralismo, lo cual permitiría superar a los modelos pluralistas superficiales y seculares, así como a su conexa idea de una nación fuertemente centralizada (Pérez, 2017: 13-14).

Por un lado, su pluralismo es profundo dado que el modelo es, ante todo, uno que alcanza todas las esferas de la vida de los individuos: dada la imposibilidad de separar lo público de lo privado, toda propuesta para la organización de una sociedad debe dar cuenta necesariamente de ambas esferas, tendiendo así a una concepción de las nociones de libertad de expresión y acción que respete los hábitos, rituales y creencias de cada persona (Pérez, 2017: 14). Por otro lado, su pluralismo es multidimensional, dado que mientras más se expandan los principios pluralistas a diversos ámbitos de la sociedad, ello permitiría que sean influenciadas más esferas, emergiendo así nuevas minorías. A su vez, al existir una mayor cantidad de identidades minoritarias, las necesidades de cada una pueden ser defendidas de manera conjunta, gracias al sentimiento de solidaridad que surgiría de la convivencia (Pérez, 2017: 15).

En síntesis, W. Connolly propone abandonar la definición de nación como "una mayoría central rodeada de minorías", ofreciendo en su lugar la de "minorías conectadas a través de múltiples líneas de afiliación", lo cual requeriría necesariamente de la ampliación en el ámbito estatal de diversidades legítimas, así como la reducción de aquellas prácticas que se consideren ofensivas para cada una de ellas (Pérez, 2017: 15).

En el segundo enfoque cabe ubicar el trabajo de R. Dahl, quien afirma que el modelo de democracia pluralista, a diferencia del elitista, presupone que ningún grupo está por encima de la sociedad o está en condiciones de dominarla. El pluralismo traza una nítida separación entre sociedad civil y Estado, así como aísla la esfera política de la económica. El poder, para los pluralistas clásicos, no se acumula, sino que se halla disperso, por ello el rol central del Estado es el de mediar, regular, apaciguar los conflictos que surgen al interior de la sociedad. En particular, R. Dahl señalaba que 
en un modelo pluralista hay centros de poder múltiples, ninguno de ellos enteramente soberano (Smith, 1995; García Samaniego, 2010)).

De este modo, es mediante elecciones, planteos, y demandas sociales, que se va fijando en un modelo pluralista la agenda política pública. Sin embargo, como bien aclaraba R. Dahl "el pluralismo no significa que todos los ciudadanos estén dentro del proceso político. Pone de manifiesto el hecho de que muchos ciudadanos permanecen inactivos, que los ingresos, la riqueza y los recursos políticos no están distribuidos de forma equitativa" De este modo, la esfera política para los pluralistas no es un ámbito equitativo ideal, sino una arena de libre y constante negociación que permite resolver pacíficamente nuestros conflictos y desacuerdos (Smith, 1995: 223; Nun, 2015: 38).

Particular relevancia tuvo entre los analistas políticos la resignificación que de la teoría democrática pluralista de R. Dahl efectuó el cientista político J. J. Linz quien aplicó dichos conceptos al estudio de las transiciones democráticas en Europa y América latina, tomando por ideal regulativo el poliárquico o pluralista y promoviendo activamente la parlamentarización de la política (Smith, 1997: 223). Los estándares de evaluación de las instituciones políticas pergeñados por J. J. Linz fueron los empleados por los teóricos políticos argentinos de la transición democrática, criterios que a su vez ocuparon un rol preponderante en la reforma constitucional de 1994 (Nino, 1992, 1997).

Una vez efectuada dicha distinción, corresponde señalar que este segundo enfoque es el que resulta relevante a los fines del objetivo general del presente trabajo.

\section{Algunas desventajas normativas del federalismo pluralista impro- pio.}

Por su parte, C. S. Nino sostiene que el sistema federal argentino posee graves defectos morales en términos de legitimidad democrática, originados ellos por la adopción de una concepción pluralista impropia de la democracia como base normativa justificatoria del diseño constitucional argentino. El adjetivo calificativo impropia hace alusión a la indebida concentración de funciones en manos del Poder Ejecutivo que efectúa la constitución argentina. En este sentido, cabe señalar, que una concepción pluralista propia o genuina, rechaza el desequilibrio ab initio entre poderes constituidos de gobierno (Nino, 1992, 1997). 
En términos generales, C. S. Nino efectuaba dos objeciones principales al modelo democrático pluralista.

En primer lugar, el criterio de unificación de la concepción democrática pluralista sería el de agregación de preferencias, tomando a estas últimas como previamente fijadas al proceso de discusión política, imposibilitando así la transformación de unas preferencias en otras e impidiendo que las preferencias individuales se ordenen hacia una idea pública compartida. En segundo lugar, la concepción democrática pluralista pareciera favorecer el mantenimiento de la actual distribución de poder económico social y político, atento impone una mayoría muy gravosa para posibilitar el cambio del estatus quo, lo cual permite que pervivan las situaciones de injusticia o ilegitimidad preexistentes al debate democrático, sino se logra una mayoría agravada o supermayoría de voluntades ciudadanas (Nino, 1992: 579-580).

En términos específicos, los defectos normativos propios del federalismo argentino, bajo una concepción pluralista impropia de la democracia a los cuales refiere C. S. Nino son los siguientes: 1) dispersión de soberanía; 2) deficiente procesamiento del consenso colectivo; 3 ) mediación imperfecta; 4) apatía política; y 5) empobrecimiento del debate público (Nino, 1992: 577).

En primer lugar, el problema de la dispersión de soberanía se produce debido a que el sistema federal pluralista propone explícitamente una dispersión temporal, espacial y funcional de la soberanía popular. La dispersión temporal se da debido a la división entre leyes ordinarias (decretos, decretos-leyes, normas legislativas) y extraordinarias (constitución originaria y reformas constitucionales), en tanto decisiones políticas tomadas en momentos disímiles, siendo particularmente vinculantes las decisiones previas y extraordinarias con relación a las ordinarias posteriores. La dispersión espacial se debe a la distribución del poder político en unidades geográficas disímiles y compatibles (nacional, provincial, municipal) (Nino, 1992: 577, 580-588). La dispersión funcional se debe a que en un mismo plano temporal y espacial intervienen distintos representantes políticos todos ellos legitimados para desempeñar un rol o función específica. La concepción pluralista democrática se propone con la adopción de dicha triple dispersión evitar la tiranía de la mayoría y de la minoría (Nino, 1992: 577-578; 588-591).

Conforme, C. S. Nino, el resultado de estos tres tipos de dispersión de la soberanía popular, es un fuerte debilitamiento de la calidad o valor epistémico de la democracia constitucional argentina. Este debilitamiento epistémico se debe a la dificultad de combinar la voluntad política 
expresada en momentos, espacios y por funcionarios diferentes, en una única decisión general que sea representativa de la opinión de la mayoría de los ciudadanos (Nino, 1992: 577-578).

En otras palabras, la voluntad política presidencial es independiente de la voluntad política popular. Dicha independencia no solo está dada en tanto no está obligado el primer mandatario a seguir las opiniones de sus ciudadanos, sino en cuanto también es incapaz de dar cuenta adecuadamente de los cambios o fluctuaciones en las opiniones políticas de los ciudadanos (Nino, 1992: 584).

El defecto normativo que ostenta aquí el gobierno argentino es que concentra en un ámbito espacial de poder (nacional) la capacidad de discusión y decisión de temas que originariamente debieran ser discutidos y decididos en otras esferas espaciales de poder más descentralizados (provincial y/o municipal), lo cual garantizaría una mayor consistencia entre el resultado del debate (decisión política) y las opiniones individuales de los participantes, así como un mayor conocimiento por la inmediatez física de los problemas políticos discutidos de la mayor o menor eficacia de las posibles medidas a adoptar (Nino, 1992: 586).

El poder ejecutivo ha acaparado un gran número de herramientas constitucionales que hacen fracasar desde el inicio el mito originario de guerra justa entre poderes constituidos para el equilibrio y el fin último pluralista de armonía del sistema constitucional (Nino, 1992: 588). Por otro lado, C. S. Nino señala que “...el sistema presidencialista, que admite dos órganos con la misma legitimidad de origen pero con diferentes mecanismos de transformación de votos en cargos y operando con secuencias temporales distintas, descompone el resultado del debate público de tal forma que no permite garantizar el consenso, que es el resultado de ese debate, se traduzca en directivas de acción política unívocas" (Nino, 1992: 588).

$\mathrm{Al}$ respecto, C. S. Nino señala que en el marco del sistema político argentino, es muy poco probable que el poder ejecutivo y el legislativo nacional recepten adecuadamente el consenso existente entre ciudadanos provinciales acerca de determinados temas políticos (Nino, 1992: 589590). Generalmente el poder legislativo y el poder ejecutivo, si no poseen un mismo signo político, poseen fuertes incentivos para obstruirse mutuamente, sea mediante la sanción de leyes que van contra las perspectivas política del ejecutivo o bien mediante vetos totales o parciales de las leyes del congreso (Nino, 1992: 590-591). 
En segundo lugar, el problema macro de deficiente procesamiento del consenso colectivo alude según C. S. Nino a que ni el poder ejecutivo ni el poder legislativo nacional pueden identificar e instrumentalizar en normas, instituciones y/o políticas públicas, aquellos consensos deliberativos considerados relevantes por la comunidad política a la cual representan (Nino, 1992: 592).

El deficiente procesamiento del consenso colectivo posee para C. S. Nino diferentes causales. En otras palabras. al interior de este problema o dificultad normativa macro del sistema federal, C. S. Nino menciona tres problemas o defectos micro, a saber: 1) la posibilidad de elección de presidentes con escasa legitimidad democrática de origen; 2) la concepción agonal de la política electoral entendida como un juego de suma cero; 3 ) la falta de adecuadas herramientas para procesar los desacuerdos políticos sin resignar estabilidad democrática; y 4) la predominancia de un criterio de legitimación personalista por sobre un criterio de legitimidad dialógico (Nino, 1992: 592-593). Especial relevancia reviste para nuestro objeto de análisis los ítems 3 y 4.

En relación al tercer problema micro, atinente a la inexistencia de herramientas jurídicas adecuadas para identificar y procesar los profundos, persistentes e inerradicables conflictos que se dan en toda sociedad democrática contemporánea, resulta evidente que ante graves crisis políticas, económicas, sociales causadas o no por graves faltas o errores del gobierno presidencial, el diseño federal argentino no provee salidas expeditas, pertinentes y sensibles a las necesidades públicas de la ciudadanía en general (Nino, 1992: 593).

En este sentido, la constitución nacional argentina no define una válvula de escape ante situaciones de crisis en la estabilidad del gobierno presidencial. El jefe de gabinete de ministros no tiene la atribución constitucional de reemplazar al presidente ante casos de ausencia temporal o permanente o remoción de este.

En cuanto al cuarto problema micro, relativo al personalismo político, debe señalarse que el rol cuasi omnipotente que la constitución nacional argentina otorga al presidente de la nación lleva habitualmente a que dicho primer mandatario sustente sus medidas políticas en un liderazgo carismático e incluso en ocasiones mesiánico. Los grandes y numerosos poderes requieren grandes y numerosas operaciones de legitimación constantes. Esto atenta contra las mandas de la democracia deliberativa, la cual requiere que toda norma, institución o medida política este legitimada 
moralmente en un proceso amplio y discursivo que incluya las voces de todos los afectados y que impida que solo algunos ciudadanos o uno solo de ellos monopolice el proceso de debate y decisión política (Nino, 1992: 593).

Conforme C. S. Nino, dicha falta de correlación entre consensos ciudadanos y medidas de gobierno explica porque en el federalismo argentino se dan: a) un apartamiento considerable de aquellas condiciones que otorgan valor epistémico al funcionamiento del gobierno democrático; y b) resultados tan deficitarios en términos de legitimidad moral (Nino, 1997: 247).

En tercer lugar, el problema macro de la mediación imperfecta se origina debido a ciertos defectos existentes en el sistema de representación política argentina.

Al respecto, C. S. Nino señala que la concepción de la idea de representación política más coherente con la democracia deliberativa es la que entiende a la representación como una delegación de los ciudadanos hacia los representantes para que los segundos continúen con el proceso de discusión y decisión pública iniciado por los primeros (Nino, 1992: 587).

A su vez, C. S. Nino señala que la idea de representación es ineludiblemente dual. Es decir, su definición de representación se compone de dos elementos: i) mandato-responsabilidad; y ii) semejanza-proximidad. Por un lado, la representación refiere a las nociones de responsabilidad y mandato, atento solo se puede ser representante quien asuma la responsabilidad de actuar en nombre de otro y la evaluación del accionar del representante depende del cumplimiento de su mandato. Por otro lado, la representación implica que una persona se sustituye por otra, debiendo ser esta última semejante en los aspectos relevantes (Nino, 1992: 598).

Teniendo en cuenta estas dos precisiones C. S. Nino señala que el sistema federal argentino, no permite una adecuada representación de los intereses públicos plasmados en el consenso político existente entre los ciudadanos electores, ya que: a) no posibilita que su máximo representante, es decir el presidente de la nación, continúe el proceso de deliberación y decisión pública iniciado por los ciudadanos provinciales, y b) se acentúa uno de los elementos de la definición de representación (mandato-responsabilidad) por sobre otro (semejanza-proximidad), siendo sin embargo imposible obligar constitucionalmente y fehacientemente al presidente a cumplir con aquellas promesas que le permitieron acceder a su cargo (Nino, 1992: 598$600)$. 
En cuarto lugar, el problema macro de la apatía política es tal debido a que la concepción democrática pluralista impropia no genera los incentivos políticos necesarios para que los ciudadanos se involucren de forma activa y comprometida con la cosa pública. El federalismo bajo una perspectiva pluralista impropia presupone que las preferencias políticas ciudadanas son configuradas de forma previa al debate, siendo entonces muy limitada o nula la posibilidad de que durante el debate se produzca genuinamente un cambio. Ello desincentiva notoriamente a los ciudadanos, depositando entonces por completo la posibilidad de deliberar y decidir en sus representantes políticos (Nino, 1992: 605-606).

A ello debemos sumar la existencia de un sistema hiperpresidencial que restringe hasta límites insospechados al sistema federal pluralista impropio, lo cual implica la implementación de un diseño político de gobierno que instrumenta un proceso de deliberación y decisión política de tipo centralista y vertical, que concentra numerosas funciones en el poder Ejecutivo, por oposición a un sistema descentralizado y horizontal del poder. Estos caracteres de centralidad y verticalidad, hace que los ciudadanos no posean incentivos, mecanismos ni lugares donde participar activamente de la discusión y decisión política en cuestiones relevantes (Nino, 1992: 612).

En quinto lugar, C. S. Nino señala que el problema macro del empobrecimiento del debate público constituye una de las razones principales por las cuales cabe afirmar el escaso valor epistémico del proceso democrático de discusión y decisión política propio del sistema federal argentino.

De este modo, C. S. Nino identifica cinco circunstancias negativas propias del sistema político argentino que contribuyen a la pobre calidad de la discusión pública.

En primer lugar, el hiperpresidencialismo argentino constituye una de las principales causales del bajo nivel de discusión política en Argentina. El presidencialismo argentino implica adoptar una forma de hacer política de tipo personalista, agonista, caudillista, que promueve discursos y programas de gobierno ambiguos e inconsistentes. En segundo lugar, la pobre calidad de la deliberación política en Argentina se debe a la baja calidad del debate parlamentario, es decir al efectuado en las cámaras de diputados y senadores. En tercer lugar, no existe en la Argentina un equitativo acceso a los medios de comunicación masiva, lo cual imposibilita que los ciudadanos estén debidamente informados y que se escuche la 
pluralidad de voces y perspectivas que existen entre los ciudadanos. En cuarto lugar, las campañas políticas son meramente agresivas o negativas, atento no proponen ideas o acciones positivas sino un concierto de críticas a la persona o perspectiva de los rivales de turno, además se centran en las figuras personales de los candidatos y son muy poco transparentes en cuanto a sus fuentes de financiación. De este modo, los partidos políticos no brindan un genuino menú de opciones divergentes entre las cuales optar, sino programas vagos de gobierno, y candidatos que se cansan de prometer medidas que nunca se concretarán. En quinto lugar, existe una causal cultural o educativa, a saber: no existe una tradición cívica de justificación racional de las medidas políticas individuales y colectivas (Nino, 1992: 613-617).

Por su parte, J. F. González Bertomeu se propone emplear tres criterios normativos desde los cuales evaluar la mayor o menor legitimidad de las distintas concepciones normativas del término federalismo y sus respectivos diseños institucionales. Estos tres criterios son: a) el grado y calidad de deliberación y control democrático promovido; b) la protección de las preferencias de ciertos grupos minoritarios; y c) la protección de las preferencias de los grupos mayoritarios (González Bertomeu, 2008: 444).

En cuanto al primer criterio normativo, en esta empresa normativa evaluativa el autor asume una particular concepción del concepto de democracia sustentada en una versión contemporánea del republicanismo cívico, nutriéndose de los aportes de autores tales como P. Pettit, aunque pudiera de haber incluido allí a F. Ovejero Lucas, J. L. Martí y F. Lovett. Esta perspectiva republicana cívica señala que “...el sistema político debe ser diseñado con el fin de minimizar la posibilidad de que un individuo o grupo se situé por encima de otros dominándolos, y de aportar a la deliberación y el autogobierno colectivos..." (González Bertomeu, 2008: 444). De este modo, en sociedades complejas y amplias en población, el federalismo le permite al sistema democrático minimizar, acotar o limitar la posibilidad de que el estado nacional domina a los ciudadanos. Ello sería posible dado que la federación pone “.... disposición de los individuos un ámbito adicional, más cercano y local, tanto como esfera autónoma de participación cuanto como modo de experimentación y preparación para (saltar a) las discusiones a nivel nacional..." (González Bertomeu, 2008: 445).

En relación con el segundo criterio normativo, relativo a la protección de las preferencias políticas de grupos minoritarios, cabe 
afirmarse que "...los arreglos federales podrían estar en mejores condiciones de minimizar la posibilidad de dominación de un grupo sobre otros. Pero esto podría ser así sólo si el peligro de abusos proviniera del propio Estado central..." (González Bertomeu, 2008: 446). Este efecto positivo se daría mediante dos acciones diversas promovidas desde un esquema federal de gobierno. Por un lado, el mismo adiciona ciertos niveles de deliberación y decisión política que permitirían filtrar o impedir la dominación del gobierno nacional central sobre los gobiernos locales. Por otro lado, permitiría a las unidades políticas subnacionales constituirse en actores políticos fundamentales en el proceso de decisión nacional. No obstante, la existencia de actores locales con poder de veto en el proceso deliberativo y decisional nacional sería atractivo, si y solo si, se implementa en casos de grupos minoritarios no dispersos geográficamente, es decir si estamos ante minorías concentradas, mientras que sería contraproducente al ideal republicano si los miembros del grupo minoritario estuvieran desperdigados en diversas unidades políticas subnacionales (González Bertomeu, 2008: 446-449).

En relación con el tercer criterio normativo evaluativo, parecería que el federalismo posee una conexión problemática con el principio o regla democrática de la mayoría, ya que la multiplicación y fragmentación del proceso deliberativo y decisorio nacional podría impedir la adopción y aplicación de instituciones, normas y medidas políticas preferidas por un grupo político mayoritario (González Bertomeu, 2008: 450).

Desde una perspectiva democrática pluralista, el federalismo sería visto como un arreglo institucional que impide y dificulta la formación de una clara voluntad mayoritaria nacional (González Bertomeu, 2008: Nota a pie $\mathrm{N}^{\circ} 18$ ). Ahora bien, esta conclusión no sería de tal magnitud si estuviéramos frente al caso de un sistema federal con un legislativo bicameral en el cual la relación entre las cámaras fuera asimétrica, otorgando mayor poder deliberativo y decisor a la cámara que representa al pueblo de la nación. Mientras que si la relación entre ambas cámaras es simétrica se produciría una notoria disrupción en el proceso de conformación de una política nacional mayoritaria (González Bertomeu, 2008: 451-452). Cabe destacar que la concepción del término mayoría aquí asumida por el autor no es de tipo liberal agregativa, conforme la cual las preferencias políticas son previas y predeterminadas al proceso de deliberación y decisión política. En la perspectiva republicana deliberativa asumida, las preferencias políticas, así como los principios políticos mismos desde las cuales las mismas 
son evaluadas, son parcialmente dependientes del proceso deliberativo y decisorio, siendo entonces necesario cierto desequilibrio entre cámaras para alcanzar argumentos que respeten las preferencias políticas de todos los afectados por dicha institución, norma o medida política concreta a sancionar (Martí, 2006).

Atendiendo a lo señalado por J. F. González Bertomeu, podría afirmarse que el vigente sistema federal argentino, de tipo pluralista impropio, no satisface adecuadamente aquellos tres estándares normativos.

En primer lugar, el sistema federal argentino no promueve la deliberación entre provincias, ni posibilita un genuino control ciudadano de las instituciones públicas. Por un lado, la constitución nacional argentina de 1994 emplea como criterio normativo de decisión el de negociación, el cual no arroja beneficios epistémicos intersubjetivos al proceso de discusión y decisión política federal. Por otro lado, la Nación domina a las provincias mediante la imposición de un fuerte sistema presidencial, así como permite que ciertas comunas, provincias o regiones dominen a aquellas otras que ostentan menor capacidad de negociación adquirida.

En segundo lugar, los grupos minoritarios especialmente desaventajados no son adecuadamente protegidos, dado que: a) no se otorga a las comunas, provincias o regiones un genuino poder de veto político en aquellos procesos formales de sanción de leyes federales que les tengan como destinatarios exclusivos o protagonistas; $y$ b) dichos grupos minoritarios especialmente desaventajados se encuentran generalmente dispersos en la geografía nacional, sin contar con mecanismos institucionales apropiados que les permitan presentar sus reclamos, propuestas u objeciones de forma conjunta, unificada o cooperativa.

En tercer lugar, la controversial relación entre sistema federal de gobierno y principio político mayoritario se profundiza en dos sentidos. Por un lado, se agudiza, dado que ambas cámaras legislativas del Poder Legislativo Nacional (Diputados y Senadores), poseen una relación simétrica de fuerzas en el proceso de sanción formal de las leyes federales. Por otro lado, el bicameralismo permite que los intereses generales, federales, nacionales sean por definición diferentes, disímiles e incluso opuestos a los provinciales. Ambas deficiencias normativas, en modo alguno se subsanan otorgando la posibilidad de oficiar de cámara de origen a la de senadores, en ciertos casos explícitamente establecidos por la constitución nacional, ya que no se promueve una deliberación entre sujetos políticos subnacionales, sino entre representantes de dichas entidades, ni tampoco se 
emplean órganos, mecanismos o dispositivos ciudadanos provinciales de control político.

\section{Un modelo federal democrático deliberativo.}

En respuesta a cada una de dichas objeciones formuladas contra un modelo federal pluralista impropio, esbozaremos una propuesta de solución, que si bien es coherente con la defensa de una concepción democrática deliberativa, sin embargo no implica el reemplazo de nuestro sistema federal por otro confederal, ni el presidencial por un sistema parlamentario, sino más bien una profunda reforma que conllevaría la adopción de un sistema federal deliberativo y un sistema semipresidencial de gobierno

\section{El sistema federal argentino desde una concepción democrática de- liberativa.}

En oposición a la concepción democrática pluralista, la democracia deliberativa constituye una concepción normativa de la democracia conforme la cual los ciudadanos y sus representantes deben dar razones mutuamente aceptables acerca de porque debe considerarse justificada la adopción de una medida, norma o institución política. ${ }^{5}$

En cuanto al concepto de democracia deliberativa, puede desglosarse en tres elementos (E) necesarios y suficientes, a saber: E1) ideal regulativo; E2) sujeto; y E3) proceso.

E1) Ideal regulativo (qué): el concepto de democracia deliberativa sostiene que el principio político de toma de decisiones a adoptar es el de argumentación racional, el cual permite y promueve la transformación de las preferencias políticas de los ciudadanos. De este modo, las normas, medidas e instituciones políticas son democráticamente legítimas si y solo si resultan de la deliberación pública entre ciudadanos y representantes,

$5 \quad$ Sobre el concepto de democracia deliberativa, se han esbozado en la literatura especializada distintas interpretaciones o concepciones. Tomando en cuenta como criterio clasificatorio central la concepción de libertad política adoptada, pueden identificarse al menos tres concepciones deliberativas, a saber: a) liberal; b) ética discursiva; y c) republicana. Por un lado, al interior de la concepción deliberativa liberal destacan las teorizaciones de: J. Rawls (1996); C. S. Nino (1997); S. Linares (2017); y A. Gutmann y D. Thompson (1996, 2004). Por el otro, son partidarios de una concepción deliberativa ética discursiva, los siguientes pensadores: J. Habermas (2005); J. Dryzek (2000); C. Rostbøll (2008). En tercer lugar, la concepción deliberativa republicana puede subclasificarse en: a) republicana clásica (Aristóteles); y b) republicana cívica (J. L. Martí, 2006). 
y están justificadas en aquellas razones públicas que resultan aceptables para los deliberantes. Este ideal regulativo alberga un conjunto de principios políticos procedimentales y sustantivos que permiten evaluar normativamente las medidas, normas o instituciones democráticas reales. El contenido y forma de estos principios es parcialmente dependiente de la deliberación real y parcialmente independiente de ella.

E2) Sujeto (quienes): La democracia deliberativa postula que todos los ciudadanos deben considerarse moral y epistémicamente capacitados para intervenir en el debate público y tomar decisiones políticas, razón por la cual durante el proceso deliberativo deben escucharse, respetarse, y discutirse los argumentos de todos los posibles afectados por la norma o medida política en cuestión. El proceso deliberativo debe aspirar a cumplir con los ideales regulativos de inclusión, igualdad política e imparcialidad. Los ciudadanos deben tratarse unos a otros como personas libres e iguales con capacidad de autogobierno político. Desde una concepción deliberativa, los resultados de la deliberación democrática son valiosos por su calidad epistémica y por permitir dicho trato igualitario entre ciudadanos. La concepción deliberativa considera que los ciudadanos al deliberar deben tener por horizonte normativo una idea más o menos clara de bien común, así como desarrollar determinados aspectos de su personalidad. De este modo la democracia deliberativa considera necesaria pero insuficiente la adopción del principio de la mayoría, debiendo ser el mismo complementado con el principio de reciprocidad moral o civilidad cívica, el cual requiere la adopción de un punto de vista imparcial.

E3) Proceso (cómo): el ideal regulativo deliberativo es puesto en práctica por ciertos sujetos mediante la implementación de un proceso de discusión y decisión política. El ideal democrático deliberativo adopta un criterio epistémico intersubjetivo de validación de los resultados alcanzados. En dicho marco, el proceso democrático deliberativo es entendido como un proceso autocorrectivo, cuyos resultados son provisionales ya que están sometidos a continua revisión. La concepción deliberativa asume como una de sus hipótesis centrales que los resultados del proceso deliberativo no son infalibles, sino revisables. El proceso democrático deliberativo tiene por objetivos centrales: a) promover el trato igualitario entre ciudadanos; así como b) facilitar la resolución de aquellos desacuerdos políticos existentes al interior de una determinada sociedad, tendiendo al logro de un consenso racional entre los deliberantes. 


\section{Las ventajas normativas del federalismo deliberativo por sobre el federalismo pluralista impropio.}

Habiendo explicitado distintas objeciones dirigidas a la concepción pluralista (3.2), y las bases normativas de una concepción deliberativa del sistema federal (4.1.), ahora nos abocaremos a esgrimir argumentos en defensa de este diseño institucional deliberativo sui generis superador de la propuesta federal pluralista.

La incógnita principal por responder es entonces la siguiente ¿ $\mathrm{el}$ federalismo deliberativo supera los defectos normativos propios del sistema federal pluralista impropio señalados por C. S. Nino y F. González Bertomeu?

En respuesta a esta incógnita, procederemos atendiendo al orden en que dichos defectos fueron presentados.

En primer lugar, consideramos que la implementación de un diseño federal deliberativo en Argentina permitiría superar o bien matizar fuertemente los defectos normativos propios de la concepción pluralista impropia de la democracia a los cuales refiere C. S. Nino, a saber: 1) dispersión de soberanía; 2) deficiente procesamiento del consenso colectivo; 3) mediación imperfecta; 4) apatía política; y 5) empobrecimiento del debate público (Nino, 1992: 577).

En otras palabras el federalismo argentino, tras adoptar un diseño institucional democrático deliberativo, tendrá las siguientes cinco ventajas normativas: 1) la soberanía seguirá dispersa en el plano espacial por motivos de descentralización política, pero no así en el plano temporal y funcional; 2) el consenso colectivo será procesado más adecuadamente; 3 ) la mediación efectuada por los representantes seguirá siendo perfectible pero estará orientada a continuar la deliberación en los foros institucionales en los cuales se desempeñen; 4) la apatía política se verá reducida atento los mayores incentivos cooperativos que ofrece este diseño para representantes y representados; y 5) el debate público se verá claramente enriquecido por las deliberaciones existentes en los foros formales e informales.

En primer lugar, recordemos que el problema de la dispersión de soberanía se produce debido a que el sistema presidencial pluralista propone explícitamente una dispersión temporal, espacial y funcional de la soberanía popular (Nino, 1992: 577). Detrás de este defecto normativo existe según C. S. Nino un criterio meramente agregativo de las preferencias ciudadanas. Frente a dicho problema el criterio de unificación de las 
voluntades ciudadanas propio de la concepción democrática deliberativa es el de acomodación de preferencias, siendo estas últimas parcialmente construidas durante el proceso de discusión política, posibilitando así la transformación de unas preferencias en otras y posibilitando así que las preferencias individuales se ordenen hacia una idea pública compartida. A su vez, la concepción democrática deliberativa pareciera favorecer el cambio de la actual distribución de poder económico social y político, atento impone una mayoría simple (no gravosa) para posibilitar el cambio del estatus quo, lo cual permite eliminar las situaciones de injusticia o ilegitimidad preexistentes al debate democrático.

En cuanto al problema de la dispersión temporal de la soberanía popular, su más grave causal según C. S. Nino es el sistema federal centralista construido en el marco de un sistema político hiperpresidencial como el argentino (Nino, 1992: 584). De este modo la adopción de un sistema federal deliberativo permitiría eliminar la causal principal de dicho defecto normativo. Ello por numerosas razones. Por un lado, las medidas políticas a adoptar por el presidente de la república argentina permitirían reflejar, es decir, dar cuenta del consenso político que implicó su elección. La flexibilidad del mandato presidencial deliberativo, así como la variedad de causales taxativas que habilitan el proceso de remoción del presidente, permitirá que durante todo el período constitucional de su gobierno las medidas presidenciales sean consistentes con las opiniones políticas de los ciudadanos argentinos. En otras palabras, la voluntad política presidencial es parcialmente dependiente de la voluntad política ciudadana y parcialmente independiente y autónoma de ella. Dicha dependencia parcial no solo está dada porque el primer mandatario está obligado a seguir las opiniones de sus ciudadanos, sino en cuanto también es capaz de dar cuenta adecuadamente de los cambios o fluctuaciones en las opiniones políticas de dichos ciudadanos.

El problema de la dispersión espacial se debe en argentina a su forma federal de gobierno, la cual promueve la existencia de tres tipos de unidades políticas, nacional, provincial y municipal, que definen mediante negociación y voto. La ventaja normativa que ostenta aquí el federalismo deliberativo es que desconcentra en varios ámbitos espaciales de poder el proceso de discusión y decisión de temas políticos centrales, los cuales se resuelven mediante argumentación. Este cariz descentralizado del federalismo deliberativo respeta la aspiración de la democracia deliberativa de que la unidad geográfica de decisión sea tan pequeña como sea posible. 
En principio, el carácter descentralizado, más horizontal y el tamaño pequeño de las unidades de decisión, garantiza una mayor consistencia entre el resultado del debate (decisión política) y las opiniones individuales de los participantes (argumentos políticos), así como un mayor conocimiento de los problemas políticos concretos y por ende una mayor eficacia política (Nino, 1992: 586).

De este modo, el federalismo deliberativo posibilitaría la implementación de aquellas soluciones exploradas por C. S. Nino, frente al problema de la dispersión espacial, a saber: a) descentralización profunda de las decisiones políticas, lo cual daría mayor legitimidad a cada decisión política aisladamente considerada, y generaría suficientes incentivos de cooperación entre las unidades más pequeñas y últimas de discusión y decisión; b) la división de los procesos democráticos según un criterio cooperativo funcional, en el que cada nivel de gobierno (nacional, provincial, o municipal) se desempeña en una específica e irremplazable tarea de discusión, decisión, o implementación de una determinada norma, institución o medida política (Nino, 1992: 587-588). A dichas soluciones o medidas, podría sumarse una tercera y una cuarta, a saber: c) la existencia de cuerpos colegiados interjurisdiccionales de ciudadanos agrupados por temas de interés nacional. Es decir grupos políticos (demoi) de orígenes provinciales o municipales diversos unidos por el interés en dar una respuesta específica o evaluar una misma problemática política nacional; y d) la implementación de cuerpos ciudadanos colegiados con funciones específicas y taxativas de control político del accionar de los representantes políticos que actualmente se desempeñen en los poderes constituidos (legislativo, ejecutivo y judicial).

El problema de la dispersión funcional se conecta claramente con la discusión relativa a cuál es la más adecuada relación entre poderes constituidos a efectuar al interior de una república democrática. En el caso del sistema federal deliberativo, por un lado, pone en diálogo al poder ejecutivo con el poder legislativo y judicial. En este sentido, el poder ejecutivo, en el marco de un sistema federal deliberativo, acapara un reducido número de herramientas constitucionales que hacen posible desde el inicio el mito originario de cooperación deliberativa razonada entre poderes constituidos. Por otro lado, el sistema federalista deliberativo, admite dos órganos con la misma legitimidad de origen pero con un mismo mecanismo de transformación de votos en cargos permite obtener un consenso medianamente amplio y razonable, en tanto resultado del debate 
político, el cual tiene pretensiones de traducirse en directivas comunes de acción política.

Al respecto, en el marco del sistema federal deliberativo propuesto, sería altamente probable que el poder ejecutivo y el legislativo recepten adecuadamente el consenso existente entre ciudadanos acerca de determinados temas políticos. En caso de que se diera una efectiva recepción por parte de dichos órganos del consenso político resultante de la deliberación democrática, contaríamos con las herramientas constitucionales $\mathrm{y} / \mathrm{o}$ legales para posibilitar una adecuada y genuina coordinación de ambos órganos.

En segundo lugar, el problema de deficiente procesamiento del consenso colectivo sería resuelto, atento en el marco de un sistema federal deliberativo, el poder ejecutivo y el poder legislativo podrían identificar e instrumentalizar en normas, instituciones y/o políticas públicas, aquellos consensos deliberativos considerados relevantes por las comunidades políticas locales, sean provinciales o municipales a la cual representan.

El eficiente procesamiento del consenso colectivo se sustenta en diferentes causales. En otras palabras, esta ventaja normativa macro del sistema federal, implica tres ventajas micro, a saber: 1) la posibilidad de elección de presidentes con amplia legitimidad democrática de origen; 2) la concepción dialógica de la política electoral entendida como un juego cooperativo de tipo altruista moderado; 3) la existencia de adecuadas herramientas para procesar los desacuerdos políticos sin resignar estabilidad democrática; y 4) la predominancia de un criterio de legitimidad colectiva por sobre un criterio de legitimación personalista. Al respecto, como hemos anticipado, reviste particular interés para nuestros propósitos argumentativos los ítems 3 y 4 .

En relación a la tercera ventaja micro, relativa a la existencia de herramientas jurídicas adecuadas para identificar y procesar los profundos, persistentes e inerradicables conflictos que se dan en toda sociedad democrática contemporánea, resulta evidente que ante graves crisis políticas, económicas, sociales causadas o no por graves faltas o errores del gobierno presidencial, el diseño federal deliberativo provee salidas medianamente expeditas, pertinentes y sensibles a las necesidades públicas de la ciudadanía en general.

En este sentido, tras adoptar un diseño federal deliberativo, la constitución nacional argentina incluiría varias válvulas de escape ante situaciones de crisis en la estabilidad del gobierno presidencial. El 
vicepresidente y jefe de gabinete de ministros tendrían en dicho esquema la atribución constitucional de reemplazar al presidente ante casos de ausencia temporal o permanente o remoción de este.

En cuanto a la cuarta ventaja micro, relativa a la adopción de un criterio de legitimidad colectiva (no personalista), debe señalarse que el rol más moderado que la constitución nacional argentina otorgaría al presidente del estado llevaría habitualmente a que dicho primer mandatario sustente sus medidas políticas en un liderazgo dialógico cooperativo. Esto respeta las mandas de la democracia deliberativa, la cual requiere que toda norma, institución o medida política este legitimada moralmente en un proceso amplio y discursivo, que permita incluir las voces de todos los afectados y que impida que solo algunos ciudadanos o un solo ciudadano monopolice el proceso de debate y decisión política.

En tercer lugar, la ventaja de la mediación política razonable, promovida por el federalismo deliberativo, es posible debido a ciertos atractivos propios del sistema de representación política deliberativo propuesto.

Al respecto, la concepción de la idea de representación política adoptada por el federalismo deliberativo es coherente con el ideal democrático deliberativo, ya que entiende a la representación política como una delegación de los ciudadanos a sus representantes para que los segundos continúen con el proceso de discusión y decisión pública iniciado por los primeros (Nino, 1992: 587).

Teniendo en cuenta esta teoría de la representación y las precisiones relativas al sistema presidencial deliberativo argentino ya señaladas, es que consideramos que el mismo permitiría una adecuada representación de los intereses públicos plasmados en el consenso político existente entre los ciudadanos electores, ya que: a) posibilita que su máximo representante, es decir el presidente del Estado, en diálogo con su vicepresidente, jefe de gobierno y comité de ministros, continúe el proceso de deliberación y decisión pública iniciado por los ciudadanos, y b) obligando constitucionalmente y fehacientemente al presidente a cumplir con aquellas promesas que le permitieron acceder a su cargo.

Previamente advertimos que C. S. Nino reconoce dos defectos normativos principales propios de la concepción deliberativa de la representación política, a saber: 1) la representación como autorización y responsabilidad no permite en sí misma que quienes no votaron por los representante electos vean sus intereses políticos representados por quienes han ganado las elecciones e integrarán el órgano representativo; 
y 2) la representación como semejanza y reproducción no permite que los representante electos identifiquen claramente los intereses políticos a tutelar, ni que los electores identifiquen a los candidatos que podrán representar adecuadamente sus intereses políticos (Nino, 1992: 599). Estos dos defectos nacen según C. S. Nino del mantenimiento de la prohibición de establecer mandatos vinculantes, lo cual podríamos decir, implica el rechazo de una teoría de la representación como dependencia (Nino, 1992: $602)$.

Al respecto, consideramos que la solución parcial o moderación de los defectos propios de una concepción deliberativa de la representación, estaría dada por la adecuada intermediación entre representantes y representados efectuada por: a) un sistema dialógico de interacción entre partidos políticos; y b) mecanismos ciudadanos de control político.

Por un lado, dicho sistema dialógico de partidos políticos, dadas ciertas condiciones epistémicas no ideales aceptables, pueden cumplir dos valiosas funciones. Por un lado, llevan a cabo una función clarificadora y ordenadora de las opciones y alternativas ideológicas políticas existentes al interior de la sociedad democrática en la cual se desempeñan, vinculando a unos candidatos con determinadas posturas, y facilitando así a los electores un más o menos claro menú de opciones políticas. Por el otro, desempeñan una función normativa o moralizadora, obligando a que las diferentes propuestas, posturas y alternativas ideológicas brinden argumentos y razones públicas que tengan pretensiones de ser aceptables por todo el electorado, produciendo así que los programas políticos de los candidatos recurran a principios de moral pública intersubjetiva para defender la superioridad de sus ideas por sobre la de sus contrincantes políticos (Nino, 1992: 602-603).

Por otro lado, los mecanismos políticos de control ciudadano cumplirían tres valiosas funciones, en relación con el sistema político en general, a saber: a) le otorgarían legitimidad democrática; b) lo dotarían de una mayor calidad epistémica; y c) le darían al mismo mayor estabilidad política.

En cuarto lugar, el sistema federal deliberativo ofrece una razonable motivación política debido a que la concepción democrática deliberativa promovida por dicho sistema presupone que la participación directa de los ciudadanos en materia política, si bien de difícil realización, constituye un fenómeno deseable y sumamente valioso que debiera estar dado en el marco de una genuina descentralización del proceso de discusión y decisión política (Nino, 1992: 605-606). 
En otras palabras, señalamos que la concepción deliberativa del sistema federal aquí propuesto implica la implementación de un diseño político de gobierno que instrumenta un proceso de deliberación y decisión política de tipo descentralizado y horizontal, que distribuye numerosas funciones entre el poder Ejecutivo, Legislativo, Judicial y Ciudadano de nivel provincial y municipal. Estos caracteres de descentralización y horizontalidad, hace que los ciudadanos posean incentivos, mecanismos y lugares donde participar activamente de la discusión y decisión política en cuestiones relevantes (Nino, 1992: 612).

En quinto lugar, la ventaja del enriquecimiento del debate público constituye una de las razones principales por las cuales cabe afirmar el amplio valor epistémico del proceso democrático de discusión y decisión política propio de un sistema presidencial deliberativo como el propuesto para la argentina.

De este modo, podemos identificar cinco circunstancias positivas propias del sistema político federal deliberativo argentino que contribuyen a la alta calidad de la discusión pública.

En primer lugar, el federalismo deliberativo argentino constituiría una de las principales causales del alto nivel de discusión política en Argentina. El federalismo deliberativo argentino implicaría adoptar una forma de hacer política de tipo colectiva, cooperativa, dialógica, que promueve discursos y programas de gobiernos claros y consistentes.

En segundo lugar, la considerable calidad de la deliberación política en Argentina se debería a la alta calidad del debate parlamentario, es decir al efectuado en las cámaras de diputados y senadores (Nino, 1992: 615).

En tercer lugar, conllevaría a implementar en la Argentina un equitativo acceso a los medios de comunicación masiva, lo cual posibilitaría que los ciudadanos estén debidamente informados y que se escuche la pluralidad de voces y perspectivas que existen entre los ciudadanos.

En cuarto lugar, el sistema federal deliberativo propuesto obliga a que las campañas políticas sean constructivas, en un sentido mínimo, atento en dicho esquema dialógico de poder los candidatos están obligados a proponer ideas o acciones positivas, centrándose así la política más en las medidas que en las figuras personales de los candidatos y obligando a transparentar las fuentes de financiación. De este modo, los partidos políticos brindarán un genuino menú de opciones divergentes entre las cuales optar, plasmado 
en programas de gobierno medianamente claros, y candidatos que tienen ya en mente dichas medidas públicamente consensuadas (Nino, 1992: 616).

En quinto lugar, existe una consecuencia positiva de tipo cultural o educativa promovida por el diseño institucional federal deliberativo propuesto, a saber: la promoción de una tradición cívica de justificación racional de las medidas políticas individuales y colectivas (Nino, 1992: 616-617).

Retomando las teorizaciones esbozadas por J. F. González Bertomeu, cabe señalar que el modelo federal deliberativo aquí propuesto satisface ampliamente los criterios normativos por el fijados como estándares de evaluación institucional.

En primer lugar, el sistema federal deliberativo fomenta una genuina deliberación política entre comunas, provincias y regiones, así como posibilita cierto control ciudadano sobre las instituciones políticas y los representantes que transitoriamente las ocupan. Por un lado, el criterio normativo de decisión política asumido por el federalismo deliberativo es el de argumentación, con lo cual se mejora el rendimiento epistémico del proceso político. Por otro lado, dicho modelo deliberativo otorgaría a las comunas, provincias y regiones ciertas herramientas institucionales tendientes a evitar la dominación del Estado Nacional sobre ellas, así como entre ellas. Entre los mecanismos de control ciudadanos de control político, podría implementarse un tribunal ciudadano elegido por argumentos selectivos, aleatorios y meritocráticos, abocado a efectuar en ciertos casos especialmente determinados, controles de razonabilidad, constitucionalidad y convencionalidad de las medidas federales controvertidas en un caso concreto.

En segundo lugar, dicho criterio normativo argumentativo de decisión y sus correspondientes implicancias institucionales brindarían al sistema una mayor y mejor sensibilidad política frente a los reclamos de aquellos grupos minoritarios especialmente desaventajados, posibilitando su coordinación discursiva inclusive en aquellos casos de dispersión espacial de sujetos y grupos afectados. En otras palabras, resignificando las palabras de aquel autor, el modelo federal deliberativo permitiría que las comunas, provincias y regiones se constituyan en actores políticos fundamentales del proceso deliberativo y decisorio formal de sanción de leyes federales. Como consecuencia institucional, podría defenderse la existencia de un especial poder de veto a una minoría federal argumentativamente consolidada, por 
sobre aquella mayoría agregativa que va en detrimento de sus intereses políticos comunes.

En tercer lugar, en lo atinente a la relación entre sistema federal de gobierno y principio político mayoritario, el federalismo deliberativo asumiría una concepción argumentativa, no meramente agregativa, del concepto de mayoría política, con lo cual se posibilitaría la emergencia de preferencias políticas informadas y formadas durante el debate político federal, con las consabidas ganancias epistémicas que ello implica. Entre otras implicancias institucionales, podría destacarse el otorgamiento de un especial poder de veto a una mayoría federal argumentativamente consolidada, por sobre aquellas minorías que van en detrimento de los intereses políticos comunes, así como la potestad de última palabra constitucional en ciertos temas federales al senado, desplazando en dicho trascendental rol interpretativo y aplicativo a la Corte Suprema de Justicia de la Nación. En síntesis, este modelo federal deliberativo permitiría generar normas, instituciones y medidas políticas, argumentativamente justificadas y directamente controladas por sus afectados.

\section{Conclusiones.}

Este trabajo de investigación ha tenido por objetivo general reconstruir y evaluar dos modelos democráticos contemporáneos pero disímiles que tienen por epicentro el concepto de federalismo en tanto forma de gobierno. Un primer enfoque de tipo federal pluralista impropio, con elementos decisionistas, actualmente vigente en Argentina, surgió en 1994, año en el cual se sancionó la última reforma constitucional nacional. Un segundo enfoque de tipo federal deliberativo, no actualmente vigente, se propone como modelo normativo constitucional superador de aquel primero, en función de su mejor rendimiento en materia de legitimidad y estabilidad democrática.

El primer modelo federal, al cual denominamos pluralista impropio, promueve un poder ejecutivo nacional fuerte, en tanto árbitro y/o mediador en los procesos de negociación habidos entre las unidades políticas subnacionales autónomas, es decir las provincias argentinas. En este segundo discurso, el principio de resolución de conflictos es el de negociación y promueve un sistema hiperpresidencial capaz de someter a las provincias a sus criterios evaluativos los cuales están prefijados en la constitución nacional de 1994. 
El segundo modelo federal, al cual definimos como deliberativo, promueve un gobierno político suficientemente descentralizado, con una dinámica cooperativa entre poderes constituidos nacionales y entre unidades políticas subnacionales. En este segundo discurso el principio de resolución de conflictos es el argumentativo y el gobierno nacional adopta un sistema semipresidencial en el cual se evalúa el proceder de cada provincia en función de criterios preestablecidos durante un debate interprovincial previo.

Finalmente, en este trabajo hemos aportado argumentos en defensa de la hipótesis conforme la cual de adoptarse un modelo normativo deliberativo como fuente de criterios de corrección y evaluación, se verían reducidas o bien erradicadas las causales actuales de un deficiente rendimiento en materia de legitimidad y estabilidad democrática del sistema federal argentino.

\section{Bibliografía.}

AGÜERO, Alejandro.: “Autonomía por Soberanía provincial. Historia de un desplazamiento conceptual en el federalismo argentino (1860-1930)". En: Quaderni Fiorentini, N 43, 2014. Págs. 341-392.

BAZÁN, Víctor: "El federalismo argentino: situación actual. Cuestiones conflictivas y perspectivas". En: Estudios Constitucionales, Año 11, № 1, 2013. Págs. $37-88$.

BIDARTCAMPOS, German Javier: Compendio de Derecho Constitucional. Ediar, Buenos Aires, 2016.

DAHL, Robert: Dilemmas of Pluralist Democracy. Yale U. Press, New Haven, 1982.

DAHL, Robert: Democracy and Its critics. Yale U. Press, New Haven, 1997.

DALLA VIA, ALBERTO RICARDO: "Actualidad del federalismo argentino": En Serna de la Garza, José M. (coord.): Federalismo y regionalismo, Memoria del VII Congreso Iberoamericano de Derecho Constitucional. Instituto de Investigaciones Jurídicas de la UNAM, México D.F., 2002. 
DRYZEK, John: Deliberative Democracy and Beyond. Oxford U.P, Oxford., 2000.

FLAX, Javier: La democracia atrapada. Una crítica del decisionismo. Editorial Biblos, Buenos Aires, 2004.

FOLLESDAL, Andreas: "Federalism". En: The Stanford Encyclopedia of Philosophy (Edición Verano 2018), Edward N. Zalta (ed.), URL $=<\underline{\text { https: } / /}$ plato.stanford.edu/archives/sum2018/entries/federalism/>, 2018.

GARCÍA SAMANIEGO, Francisco Roberto: "Sobre el Pluralismo político, en teoría y métodos de la Ciencia Política". En: Revista de Ciencia Política, $\mathrm{N}^{\circ}$ 9, 2010.

GARGARELLA, Roberto: La sala de máquinas de la Constitución. Dos siglos de constitucionalismo en América Latina (1810-2010). Katz Editores, Buenos Aires, 2014.

GELLI, María Angélica: Constitución de la Nación Argentina. Comentada y concordada. La Ley, Buenos Aires, 2006.

GONZÁLEZ BERTOMEU, José Francisco: "Notas sobre federalismo". En: Gargarella, R. (coord), Teoría y Crítica del Derecho Constitucional, Tomo 1: Democracia. Abeledo Perrot, Buenos Aires, 2008. Págs. 439-485.

GUTMANN, Amy y THOMPSON, Daniel.: "Deliberative Democracy". En: Clarke, P. B. y Foweraker, J., Encyclopedia of Democratic Thought. Routledge, New York, 2001. Págs. 168-174.

GUTMANN, Amy y THOMPSON, Daniel: Why deliberative democracy? Princeton U.P., New Jersey, 2004.

HABERMAS, Jürgen: "Tres modelos de democracia. Sobre el concepto de una política deliberativa". En: Polis. Revista de la Universidad Bolivariana, Vol. 4, $\mathrm{N}^{\circ} 10,2005$.

HERNÁNDEZ, Antonio María: Federalismo, autonomía municipal y ciudad de Buenos Aires en la Reforma Constitucional de 1994. Depalma, Buenos Aires, 1997.

LINARES, Sebastián: Democracia Participativa Epistémica. Marcial Pons, Madrid, 2017.

LÓPEZ ROSAS, José Rafael: Historia Constitucional Argentina, 5a edición. Astrea, Buenos Aires, 1996. 
LOVETT, Frank: "Republicanism". En: http://plato.stanford.edu/archives/ sum2010/entries/republicanism/, consultado el 10/3/2013, 2010.

MARTÍ, José Luis: La República Deliberativa. Una teoría de la democracia. Serie Filosofía y Derecho. Marcial Pons Ediciones Jurídicas y Sociales, Madrid, 2006.

NINO, Carlos Santiago: Fundamentos de Derecho Constitucional. Astrea, Buenos Aires, 1992.

NINO, Carlos Santiago: La constitución de la democracia deliberativa. Gedisa, Barcelona, 1997.

NOVARO, Marcos: Historia de la Argentina. 1955-2010. Siglo XXI, Buenos Aires, 2010.

NUN, José: Democracia: ¿gobierno del pueblo o gobierno de los políticos? Capital Intelectual, Buenos Aires, 2015.

OLIVARES, Nicolás Emanuel: "Dos repúblicas rioplatenses posibles. Discursos liberales en pugna a mediados del siglo XIX". En: PolHis, Año 11, № 21, 2018. Págs. 4-38.

OVEJERO LUCAS, Félix: Incluso un pueblo de demonios: democracia, liberalismo, republicanismo. Katz, Madrid, 2008.

PALTI, Elías José: El momento romántico: nación, historia y lenguajes políticos en la Argentina del siglo XX. Eudeba, Buenos Aires, 2009.

PALTI, Elías José: Una arqueología de lo político. Regímenes de poder desde el siglo XVII. F.C.E., Buenos Aires, 2018.

PÉREZ, Moira: "Tres enfoques del pluralismo para la política del siglo XXI”. En: Ideas y Valores, Vol. 66, № 163, 2017. Págs. 1-20.

QUIROGA LAVIÉ, Humberto: Constitución de la Nación argentina comentada, Quinta Edición actualizada. Zavalia, Buenos Aires, 2012.

RAWLS, John: Political Liberalism. Oxford U.P., Oxford, 1996.

ROSANVALlON, Pierre: Por una historia conceptual de lo político. F.C.E., Buenos Aires, 2016.

RØSTBOLL, Christian Fredrich: Deliberative Freedom, Deliberative Democracy as Critical Theory. State University of New York Press, New York, 2008. 
SABSAY, Daniel Alberto: "Situación del federalismo luego de la reforma constitucional”. En: Anuario de Derecho, No 4, 1998. Págs. 279-291.

SAGÜÉS, Néstor Pedro: Manual de derecho constitucional. Segunda Edición actualizada y ampliada. Astrea, Buenos Aires, 2012.

SMITH, M.: "El pluralismo". En: Marsh, D. y Stoker, G. (eds.), Teoría y métodos de la ciencia política. Alianza Universidad Ed., Madrid, 1995. 
